\title{
Content validation of the self-care assessment scale for heart failure patients
}

\author{
Validação de conteúdo da escala de avaliação do autocuidado de pacientes com insuficiência \\ cardíaca
}

Sherida Karanini Paz de Oliveira ${ }^{1}$, Francisca Elisângela Teixeira de Lima ${ }^{2}$

\begin{abstract}
Objective: to build and validate the content of the Self-Care Assessment Scale for Heart Failure Patients. Methods: methodological study based on psychometry. A search was carried out in five databases resulting in 63 articles that guided the preparation of a preliminary instrument. Content was validated by eight judges who assessed the adequacy of each item according to the criteria: clarity, precision and relevance. Results: there was an agreement among judges of $0.896(\mathrm{p}=0.001)$, and the validity of the content of the scale was confirmed. The instrument consisted of 20 items distributed into six dimensions: Nutrition (4 items), Activity and rest (3 items), Perception and cognition (3 items), Health promotion (6 items), Stress tolerance (2 items) and Roles and Relationships ( 2 items). Conclusion: the instrument obtained a satisfactory content validity index which shows that the scale is representative of the construct content.
\end{abstract}

Descriptors: Self Care; Heart Failure; Nursing; Psychometrics; Validation Studies; Health Promotion.

Objetivo: construir e validar o conteúdo da Escala de Avaliação do Autocuidado de Pacientes com Insuficiência Cardíaca. Métodos: estudo metodológico segundo a psicometria. Realizou-se busca em cinco bases de dados, que resultou em 63 artigos que nortearam a construção de um instrumento preliminar. Procedeu-se a validação de conteúdo por oito juízes que opinaram sobre a adequação de cada item segundo os critérios: clareza, precisão e relevância. Resultados: houve uma concordância entre os juízes de 0,896 (p=0,001), sendo comprovada a validade de conteúdo da escala. 0 instrumento ficou composto por 20 itens agrupados em seis dimensões: Nutrição (4 itens), Atividade e repouso (3 itens), Percepção e cognição (3 itens), Promoção da saúde (6 itens), Tolerância ao estresse ( 2 itens) e Papéis e Relacionamentos (2 itens). Conclusão: o instrumento obteve um índice de validade de conteúdo satisfatório o que revela que a escala é representativa do conteúdo do construto. Descritores: Autocuidado; Insuficiência Cardíaca; Enfermagem; Psicometria; Estudos de Validação; Promoção da Saúde.

\footnotetext{
${ }^{1}$ Universidade Estadual do Ceará. Fortaleza, CE, Brazil.

${ }^{2}$ Universidade Federal do Ceará. Fortaleza, CE, Brazil. 


\section{Introduction}

Heart failure is a chronic illness associated to high hospital cost, resulting from several etiologies, and seen as the final stage of the majority of heart diseases. Heart failure is also a major cause of morbidity and mortality with considerable impact on thequality of life ${ }^{(1-2)}$.

Self-care of heart failure patients and successful treatment are key to improving outcomes directly linked to patient health as well as lowering mortality rates and disease-related costs. In addition, self-care deficits in this clientele are significantly associated with decreased quality of life and frequent hospitalizations $^{(3-4)}$. Thus, the accurate evaluation of the self-care of these patients is necessary, since this practice contributes to avoid decompensation crises and maintaining the patient's clinical stability.

Thus, the use of technologies to promote the health of heart failure patients, especially with regard to self-care, is important, since care technologies are known to improve the assistance ${ }^{(5)}$. Furthermore, several advantages of using technologies in nursing care have been pointed out, highlighting the innovation of care, the possibility of increasing the quality of the assistance, the systematization of the information on care for decision-making and diagnostic judgment, and greater safety in care ${ }^{(6)}$.

A review carried out in 2009 found only two self-care assessment tools specific to heart failure patients in the international literature: the Self-care Heart Failure Index and the European Heart Failure Self-care Behavior Scale, developed in the United States and the United Kingdom, respectively ${ }^{(7)}$. Yet, the use of these tools is recommended with restriction in the practice and in research, because more tests are necessary to reinforce their reliability and validity ${ }^{(8)}$.

Considering that the use of scales promotes an objective and psychometrically rigorous measure and the existing gap in the national literature about instruments based on the peculiarities of the Brazilian population, it is necessary to elaborate and disseminate tools to assess the self-care of heart failure patients.

The importance of studies on instrument building and validation consists in conveying scientific acknowledgment to the validated instrument, which will serve to direct the nursing care through reliable information.

Thus, the following question is raised: does the self-care assessment scale of heart failure patients have content validity to be used with these patients in specific, according to expertises?

The objective of this study was to build and validate the content of the Self-Care Assessment Scale for Heart Failure Patients.

\section{Methods}

This is a methodological development study that used psychometrics ${ }^{(9-10)}$ to guide the elaboration and validation of the scale.

The study was developed and organized in two phases. The first phase included the construction of the scale based on a survey in the SCOPUS, Cummulative Index to Nursing and Allied Health Literature (CINAHL), Latin American and Caribbean Literature on Health Sciences Information (LILACS), Cochrane Library and the gateway of Medical Publications (PUBMED), using the following controlled descriptors in Portuguese and English: self-care and heart failure. The studies found in the survey supported the identification and deepening of the construct "self-care in heart failure patients", its operational and constitutive definition, and the construct operationalization, which refers to the construction of the instrument (Figure 1).

\begin{tabular}{|l|c|c|c|c|c|c|}
\hline Articles & SCOPUS & PUBMED & CINAHL & COCHRANE & LILACS & Total \\
\hline Found & 1403 & 913 & 218 & 503 & 7 & 3044 \\
\hline Excluded & 1358 & 904 & 207 & 503 & 6 & 2978 \\
\hline Selected & 45 & 9 & 11 & 0 & 1 & 63 \\
\hline
\end{tabular}

Figure 1 - Distribution of the number of articles found, excluded and selected in the search carried out in the databases 
Sixty-three articles were selected. They met the following inclusion criteria: available in full-length in electronic format; published in Portuguese, English or Spanish; and addressing the guiding question. The exclusion criteria were: editorials, letters or annals of events (abstracts) and duplicate publications. There was no time restriction for publication in order to reach the largest number of publications that could contribute to the formulation of the scale items.

After selection of articles, an exhaustive and exploratory reading was performed to determine the self-care practices and the items that would compose the scale. We built a list with all the proposed items, and from this start point, we turned to the literature to confirm the practices that would be investigated in each domain.

Thus, the preparation of items to integrate the assessment tool was carried out. The result was the Self-care Assessment Scale for Heart Failure Patients. This had a Likert-type scale with five categories, ranging from 1 to 5 , where 1 represents the worst score (worst self-care) and 5 the best score (best self-care). In order to make the instrument the more objective possible, each item has elements that guide the health professional in the assessment of self-care of heart failure patients and the corresponding score in the scale.

After preparing the instrument, in the second phase, the scale was submitted to content validation by experts, including of its way of presentation.

Judges were located by searching Lattes curricula and through snowball sampling. Thirteen judges, who had clinical and/or research experience in the area of heart failure and/or self-care, were invited. One judge refused and four did not answer the invitation. Thus, eight specialists participated in the study. They received the informed consent form, a copy of the Self-Care Assessment Scale for Heart Failure Patients, an evaluation form and filling instructions. Judges offered opinions on the adequacy of each item of the scale based on clarity, precision and relevance criteria $^{(10)}$. Although the number of judges was even, there was no tie in their answers. Therefore, it was not necessary to manage disagreements.

Clarity criterion evaluates if the item is intelligible to all classes of the target population; the relevance criterion evaluates if the item is consistent with the described trait and with the other sentences that approach the same attribute. In other words, the item should not imply a different attribute than the one described. In relation to precision, the item must have a defined position in the attribute and be distinct from the others that approach the same attribute ${ }^{(10)}$.

The content validity of each item of the scale was analyzed by the Content Validity Index (CVI), which evaluates the agreement among experts regarding the representativeness of the assessment in relation to the studied content. In this method, the items and the instrument as a whole are considered valid when they obtain a CVI $\geq 0.80^{(11)}$.

The study complied with the formal requirements contained in the national and international regulatory standards for research involving human beings.

\section{Results}

In the first phase, 63 articles that contributed to the elaboration of the instrument were selected. We structured a list with all the proposed dimensions, and from this list, we turned to the literature to define the clinical references that would be investigated in each dimension.

Thus, the Self-Care Assessment Scale for Heart Failure Patients was built based on the data collected in the literature, and consisted of 29 items distributed in seven domains, namely: Nutrition, Elimination, Activity and Rest, Perception and Cognition, Health Promotion, Stress Tolerance, and Roles and Relationships.

Once the instrument was finished, the second phase of the study was carried out, in which eight judges gave an opinion on the scale. They evaluated the adequacy of the data contained in each domain of the instrument, concerning clarity, precision and relevance, analyzed by the CVI and presented in the Table 1 . 
Table 1 - Content validity index as to adequacy of the scale items in relation to clarity, precision and relevance criteria

\begin{tabular}{|c|c|c|c|c|}
\hline Item & $\begin{array}{c}\text { Clarity } \\
\text { CVI; 95\% CI }\end{array}$ & $\begin{array}{c}\text { Precision } \\
\text { CVI; 95\% CI }\end{array}$ & $\begin{array}{c}\text { Relevance } \\
\text { CVI; 95\% CI }\end{array}$ & $\begin{array}{c}\text { Degree of relevance } \\
\text { CVI; 95\% CI } \\
\end{array}$ \\
\hline 1 & $0.87 ; 0.79-0.92$ & 1.00 & 1.00 & 1.00 \\
\hline 2 & $0.75 ; 0.65-0.83$ & 1.00 & 1.00 & 1.00 \\
\hline 3 & $0.87 ; 0.79-0.92$ & 1.00 & 1.00 & 1.00 \\
\hline 4 & $0.87 ; 0.79-0.92$ & 1.00 & 1.00 & 1.00 \\
\hline 5 & $0.75 ; 0.65-0.83$ & $0.75 ; 0.65-0.83$ & $0.75 ; 0.65-0.83$ & $0.75 ; 0.65-0.83$ \\
\hline 6 & $0.87 ; 0.79-0.92$ & $0.87 ; 0.79-0.92$ & $0.87 ; 0.79-0.92$ & $0.87 ; 0.79-0.92$ \\
\hline 7 & $0.87 ; 0.79-0.92$ & 1.00 & 1.00 & 1.00 \\
\hline 8 & 1.00 & $0.87 ; 0.79-0.92$ & 1.00 & 1.00 \\
\hline 9 & $0.75 ; 0.65-0.83$ & 1.00 & $0.75 ; 0.65-0.83$ & $0.75 ; 0.65-0.83$ \\
\hline 10 & $0.25 ; 0.17-0.34$ & $0.5 ; 0.40-0.60$ & $0.37 ; 0.27-0.47$ & $0.37 ; 0.27-0.47$ \\
\hline 11 & $0.87 ; 0.79-0.92$ & 1.00 & 1.00 & 1.00 \\
\hline 12 & $0.87 ; 0.79-0.92$ & 1.00 & 1.00 & 1.00 \\
\hline 13 & $0.87 ; 0.79-0.92$ & 1.00 & $0.87 ; 0.79-0.92$ & $0.87 ; 0.79-0.92$ \\
\hline 14 & $0.87 ; 0.79-0.92$ & 1.00 & 1.00 & 1.00 \\
\hline 15 & $0.87 ; 0.79-0.92$ & 1.00 & 1.00 & 1.00 \\
\hline 16 & $0.87 ; 0.79-0.92$ & $0.87 ; 0.79-0.92$ & $0.87 ; 0.79-0.92$ & $0.62 ; 0.52-0.72$ \\
\hline 17 & $0.87 ; 0.79-0.92$ & 1.00 & 1.00 & 1.00 \\
\hline 18 & $0.87 ; 0.79-0.92$ & 1.00 & 1.00 & 1.00 \\
\hline 19 & $0.75 ; 0.65-0.83$ & 1.00 & 1.00 & $0.87 ; 0.79-0.92$ \\
\hline 20 & $0.62 ; 0.52-0.72$ & 1.00 & 1.00 & 1.00 \\
\hline 21 & 1.00 & 1.00 & 1.00 & 1.00 \\
\hline 22 & $0.87 ; 0.79-0.92$ & 1.00 & $0.87 ; 0.79-0.92$ & $0.87 ; 0.79-0.92$ \\
\hline 23 & $0.87 ; 0.79-0.92$ & 1.00 & 1.00 & 1.00 \\
\hline 24 & $0.75 ; 0.65-0.83$ & $0.87 ; 0.79-0.92$ & $0.87 ; 0.79-0.92$ & $0.87 ; 0.79-0.92$ \\
\hline 25 & $0.75 ; 0.65-0.83$ & $0.87 ; 0.79-0.92$ & $0.87 ; 0.79-0.92$ & $0.87 ; 0.79-0.92$ \\
\hline 26 & $0.62 ; 0.52-0.72$ & 1.00 & $0.87 ; 0.79-0.92$ & $0.87 ; 0.79-0.92$ \\
\hline 27 & $0.87 ; 0.79-0.92$ & 1.00 & 1.00 & 1.00 \\
\hline 28 & $0.87 ; 0.79-0.92$ & $0.87 ; 0.79-0.92$ & $0.87 ; 0.79-0.92$ & $0.87 ; 0.79-0.92$ \\
\hline 29 & $0.62 ; 0.52-0.72$ & $0.87 ; 0.79-0.92$ & $0.87 ; 0.79-0.92$ & $0.87 ; 0.79-0.92$ \\
\hline Total & $0.81 ; 0.72-0.88$ & $0.94 ; 0.88-0.98$ & $0.92 ; 0.85-0.96$ & $0.91 ; 0.85-0.95$ \\
\hline
\end{tabular}

In the clarity criterion, two maximum scores (1.0) were obtained; in the precision criterion, 20 cases of $100.0 \%$ of agreement were obtained; and in the relevance criterion, 17 maximum scores were obtained. Only the personal hygiene item received maximum agreement score for all evaluated criteria (clarity, precision and relevance). Item 10 (daytime rest) was the least clear and comprehensible item (25.0\%) and it was excluded from the instrument.

Regarding the precision criterion, items 5 (Weight control/loss/maintenance) and 10 (Daytime rest) obtained agreement of 0.75 and 0.5 , respectively, which led to the suppression of these items, since they were not considered indicators of self-care of heart failure patients.
Regarding the relevance criterion, it was verified that the 26 items were considered relevant by the judges. Therefore, three items were taken off from the first version of the self-care assessment scale of heart failure patients, namely: items 5 (Weight control/ loss/maintenance), 9 (Rest in acute decompensation) and 10 (Daytime rest). We observed that items 5 and 10 also did not reach the required agreement $(\geq 0.8)$ in the precision criterion, reinforcing its inadequacy and elimination from the scale.

The judges were also asked to consider the degree of relevance of each item in the scale and in this analysis, it was verified that there was no agreement regarding item 16 (Self-examination of feet and ankles for edema). Thus, this item was also eliminated. 
There was a statistically significant $(\mathrm{p}=0.001)$ overall agreement of 0.896 , based on the content validity index, for the Self-Care Assessment Scale for Heart Failure Patients. Thus, we can infer that the scale evaluated here has agreement, confirming its content validity.

It is important to mention that experts suggested to modify, adapt or exclude some content or restructuring some items to improve their understanding and clarity; these suggestions were accepted, as shown in Figure 2.

In total, six items were eliminated. Urinary excretion was excluded because the judges stated that this evaluation is important only for severe patients but unnecessary in stable patients. The items Self-administration of medications with cardiac side effects, Involvement in strategies that improve symptoms and Self-examination of feet and ankles were taken off the scale according to the judges' suggestion, as they believed that these items were addressed in other aspects covered in the scale. The items Weight control/ loss/maintenance and Daytime rest were considered valid, as the agreement on these items was less than $80.0 \%$.

At the end, the Self-Care Assessment Scale for Heart Failure Patients was composed of 20 items: dietary control, salt intake, water intake, daily monitoring of body weight, regular exercise, work activity, sexual activity, knowledge about heart failure, acceptance and adaptation to heart failure, monitoring for recognition of decompensation symptoms of heart failure, follow-up with health professionals, abstention from smoking, abstention from alcoholic beverages, personal hygiene, updated vaccination schedule, regular use of prescribed medication, stress management, leisure activity, seeking help when symptoms of decompensation appear and family and social support network.

These items were distributed in six domains: Nutrition (4 items), Activity and rest (3 items), Perception and cognition (3 items), Health promotion (6 items), Stress tolerance (2 items) and Roles and Relationships (2 items). The domain Elimination was excluded, as the only item in this domain (Urinary excretion), was supressed.

\begin{tabular}{|c|c|c|}
\hline Item $1^{\text {st }}$ version & Judges considerations & Item $2^{\text {nd }}$ version \\
\hline Body weight assessment & Changed & Daily monitoring of body weight \\
\hline Physical exercise & Changed & Regular physical exercise \\
\hline $\begin{array}{l}\text { The patient believes heart failure is a } \\
\text { controllable disease and that he/she can } \\
\text { adapt to it }\end{array}$ & $\begin{array}{l}\text { Joined to item The patient believes he/she } \\
\text { can be happy and healthy }\end{array}$ & Acceptance and adaptation to heart failure \\
\hline $\begin{array}{l}\text { The patient believes he/she can be happy and } \\
\text { healthy }\end{array}$ & $\begin{array}{l}\text { Joined to the adaptation item, since they } \\
\text { were considered similar }\end{array}$ & Acceptance and adaptation to heart failure \\
\hline Monitoring for symptom recognition & Changed & $\begin{array}{c}\text { Monitoring for recognition of } \\
\text { decompensation symptoms of heart failure }\end{array}$ \\
\hline Smoking practice & Changed & Abstention from smoking \\
\hline Consumption of alcohol & Changed & Abstention from alcoholic beverages \\
\hline Vaccination & Changed & Updated vaccination schedule \\
\hline Pharmacological treatment & Changed & Regular use of prescribed medication \\
\hline Stress and anxiety control & Changed & Stress management \\
\hline Social support & Changed & Family and social support network \\
\hline
\end{tabular}

Figure 2 - Distribution of altered items of the Self-Care Assessment Scale for Heart Failure Patients, after evaluation and suggestions of judges 


\section{Discussion}

At the end of the content validation, by weighing the evaluation performed by the judges, the scale was composed of six domains that included 20 items, of which 11 were modified to improve understanding and clarity, resulting in the 2 nd version of the Self-Care Assessment Scale of Heart Failure Patients. The final composition of the domains and items of the instrument will be described below.

The domains were established on the basis of the International Nursing Diagnoses (NANDA-I) domains ${ }^{(12)}$. Yet, the Self-perception, Life Principles, Safety/protection, Comfort and Growth/development domains were not included in the scale, as no self-care practices in heart failure patients related to these domains were found in the literature.

The Nutrition domain was composed of four items: Dietary control, Salt intake, Water intake and Body weight monitoring.

According to an integrative review on self-care practices of heart failure patients, salt restriction was the most frequently mentioned self-care practice in the articles analyzed (9), followed by daily weighing (8), and water restriction (7) $)^{(13)}$.

Activity and Rest was the second domain in the scale, consisting of three items: regular physical exercise, work activity and sexual activity.

The domain Perception and cognition was composed of the items Knowledge about heart failure, Acceptance and adaptation to heart failure, Monitoring for recognition of decompensation symptoms of heart failure.

Every disease, especially the chronic ones, causes disturbing feelings related to how each person views the health-disease process. Knowing the perceptions of patients with heart failure and all the subjective aspects involved, mainly in relation to chronicity, is essential. This way, nursing care can be planned and executed in a complete and effective way, effectively contributing to the patient's well-being ${ }^{(14)}$. Thus, the nurse must be attentive to these issues and empower the patient with knowledge about the disease so that this may facilitate the acceptance of the disease and adherence to changes in lifestyle.

Health promotion was the domain with more items. They include: Follow-up with health professionals, Abstention from smoking, Abstention from alcoholic beverages, Personal hygiene, Updated vaccination schedule and Rregular use of prescribed medication.

The fifth domain, Stress tolerance, had the items Stress management and Leisure activity. Besides the emotional impact that directly affects the stimulus to continue leisure activities, heart failure causes signs and symptoms that make it difficult to maintain a normal routine. Fatigue resulting from the disease can lead the individual to abandon leisure activities that give pleasure and fulfillment, due to the restrictions imposed by clinical signs ${ }^{(14)}$. The importance of this domain, due to the limitations imposed by the disease that hinders and restricts the realization of simple daily activities, was evident.

In addition, heart failure patients experience important and progressive signs and symptoms that affect the physical and psychological dimension. These clinical manifestations interfere with the daily life and also with the patients' self-esteem, directly affecting the quality of life $\mathrm{e}^{(14)}$. Emotional and psychosocial factors have a strong influence on the patient's ability to incorporate behavioral changes and healthy habits and to perform self-care for positive health outcomes $^{(15)}$.

Finally, the domain Roles and Relationships consists of the search for help when symptoms of decompensation appear and the Family and social support network. The social support network is essential to cope with a chronic illness.

Observational research pointed to the existence of a positive association between social support and empowerment, evidencing that patients with better social support have better empowerment. The 
availability of social support, from relatives, friends or other people, can contribute to the control of chronic diseases. The same authors also concluded that the social relations of the patient can facilitate or promote health protective and/or promoter behaviors and that social support is a valuable resource ${ }^{(16)}$.

The items Salt consumption, Water intake, Labor activity, Sexual activity, Leisure activity and Look for help when the patient feels bad were not changed and the items Acceptance and adaptation to heart failure, Follow-up with health professionals were the result of the joining of other items.

Nurses must act in clinical practice observing the individuals as a whole, considering them to be an active and prime participants of their health. They should seek the restoration of the clinical state and the understanding that self-care is necessary to avoid and/or minimize the number of rehospitalizations due to decompensation of the disease, and to improve the patients' quality of life $\mathrm{e}^{(17)}$.

The validity of an instrument requires a continuous process of several steps. Thus, it is important to search other types of validity, such as construct and criterion, and more precise and specific indicators.

The main implications of the study for the practice are the perspective that nurses may plan and implement individualized nursing care according to the needs of each individual, encouraging patients to correctly follow the treatment and perform self-care, besides establishing health promotion measures and to collaborating to the recognition and enhancement of the profession.

\section{Conclusion}

We conclude that the Self-Care Assessment Scale for Heart Failure Patients can be considered a validated assessment tool with confirmed content and useful to the care practice and scientific research. The instrument obtained a satisfactory content validity index, revealing that the scale is representative of the construct content.

\section{Collaborations}

Oliveira SKP and Lima FET contributed in the planning, design, analysis, interpretation of data and writing, critical review of content and final approval of the version to be published.

\section{Refereces}

1. Bocchi EA, Braga FGM, Ferreira SMA, Rohde LEP, Oliveira WA, Almeida DR, et al. III Diretriz Brasileira de Insuficiência Cardíaca Crônica. Arq Bras Cardiol. 2012; 93(6):1-71.

2. O'Connell M, Dewalt DA, Broucksou KA, Hawk $\mathrm{V}$, Baker DW, Schillinger D, et al. Relationship between literacy, knowledge, self-care behaviors, and heart failure-related quality of life among patients with heart failure. J Gen Intern Med. 2011; 26(9):979-86.

3. Seto E, Leonard KJ, Cafazzo JA, Masino C, Barnsley J, Ross HJ. Self-care and quality of life of heart failure patients at a multidisciplinary heart function clinic. J Cardiovasc Nurs. 2011; 26(5):377-85.

4. Jonkman NH, Westland $\mathrm{H}$, Groenwold RHH, Ågren S, Atienza F, Blue L. Do Self-Management Interventions Work in Patients With Heart Failure? An Individual Patient Data Meta-Analysis. Circulation. 2016; 133(12):1189-98.

5. Cestari VRF, Sampaio RLR, Barbosa IV, Studart RMB, Moura BBF, Araújo ARC. Healthcare technologies used in nursing to care for polytraumatized patients: an integrative review. Cogitare Enferm. 2015; 20(4):701-10.

6. Salvador PTCO, Oliveira RKM, Costa TD, Santos VEP, Tourinho FSV. Tecnologia e inovação para o cuidado em enfermagem. Rev Enferm UERJ. 2012; 20(1):111-7.

7. Cameron J, Worrall-Carter L, Driscoll A, Stewart S. Measuring self-care in chronic heart failure: a review of the psychometric properties of clinical instruments. J Cardiovasc Nurs. 2009; 24(6):1022.

8. Haasenritter J, Panfil EM. Assessment instruments for the measurement of the health-related selfcare of patients with heart failure. Pflege. 2008; 21(4):235-51. 
9. Pasquali L. Instrumentos psicológicos: manual prático de elaboração. Brasília: Laboratório de Pesquisa em Avaliação e Medida; 1999.

10. Pasquali L. Psicometria: teoria dos testes na psicologia e na educação. Petropólis: Vozes; 2011.

11. Rubio DM, Berg-Weger M, Tebb SS, Lee ES, Rauch S. Objectifying content validity: conducting a content validity study in social work research. Soc Work Res. 2003; 27(2):94-111.

12. Herdman TH. NANDA International nursing diagnoses: definitions and classification, 20122014. Oxford: Wiley-Blackwell; 2012.

13. Oliveira SKP, Lima FET, Pessoa VLMP, Caetano JA, Meneses LST, Mendonça LBA. Self-care practices of patients with heart failure. Rev Ciênc Méd. 2013; 22(1):23-30.

14. Oliveira TCT, Correia DMS, Cavalcanti ACD. The impact of the heart failure on daily: patient perception of follow-up ambulatory. Rev Enferm UFPE on line [Internet]. 2013 [cited 2017 Mar 13]; 7(6):4497-7. Available from: http://www. revista.ufpe.br/revistaenfermagem/index.php/ revista/article/viewArticle/4073
15. Cecilio SG, Brasil CLGB, Vilaça CP, Silva SMF, Vargas EC, Torres HC. Psychosocial aspects of living with diabetes mellitus in promoting self-care. Rev Rene. 2016; $17(1): 44-51$.

16. Cunha M, Chibante R, André S. Suporte social, empoderamento e doença crónica. Rev Portuguesa Enferm Saúde Mental [Internet]. 2014 [citado 2016 dez 13];(spe1):21-6. Disponível em: http://www.scielo.mec.pt/ scielo.php?script $=$ sci_arttext\&pid=S164721602014000100004\&lng=pt

17. Linn AC, Azollin K, Souza EN. Association between self-care and hospital readmissions of patients with heart failure. Rev Bras Enferm. 2016; 69(3):500-6. 